\title{
Associations of Sedentary Behaviour, Physical Activity, Cardiorespiratory Fitness and Body Composition with Risk of Sleep-Related Breathing Disorders in Children with Overweight/Obesity: A Cross-Sectional Study
}

\author{
Lucia V. Torres-Lopez ${ }^{1, *(\mathbb{C})}$, Cristina Cadenas-Sanchez ${ }^{1,2,3}{ }^{\oplus}$, Jairo H. Migueles ${ }^{1}(\mathbb{D}$, \\ Mireia Adelantado-Renau ${ }^{4}\left(\mathbb{D}\right.$, Abel Plaza-Florido ${ }^{1}(\mathbb{D})$, Patricio Solis-Urra ${ }^{1,5}{ }^{(1)}$, \\ Pablo Molina-Garcia ${ }^{1,6}$ and Francisco B. Ortega ${ }^{1,7}$ (D) \\ 1 PROFITH “PROmoting FITness and Health through Physical Activity” Research Group, Sport and Health \\ University Research Institute (iMUDS), Department of Physical Education and Sports, Faculty of Sport \\ Sciences, University of Granada, 18011 Granada, Spain; cristina.cadenas@uca.es (C.C.-S.); \\ jairohm@ugr.es (J.H.M.); abeladrian@ugr.es (A.P.-F.); patricio.solis.u@gmail.com (P.S.-U.); \\ pablomolinag5@gmail.com (P.M.-G.); ortegaf@ugr.es (F.B.O.) \\ 2 MOVE-IT research group, Department of Physical Education, Faculty of Education Sciences, \\ University of Cádiz, 11519 Cádiz, Spain \\ 3 Biomedical Research and Innovation Institute of Cádiz (INiBICA) Research Unit, \\ Puerta del Mar University Hospital, University of Cádiz, 11009 Cádiz, Spain \\ 4 LIFE Research Group, University Jaume I, 12071 Castellon, Spain; adelantm@uji.es \\ 5 IRyS Research Group, School of Physical Education, Pontificia Universidad Católica de Valparaíso, \\ Valparaíso 2374631, Chile \\ 6 Department of Rehabilitation Sciences, KU Leuven, University of Leuven, 3000 Leuven, Belgium \\ 7 Department of Biosciences and Nutrition, Karolinska Institutet, 14183 Huddinge, Sweden \\ * Correspondence: luciatl@ugr.es
}

Received: 14 April 2020; Accepted: 17 May 2020; Published: 20 May 2020

\begin{abstract}
The aim of this study was to examine the associations of sedentary behaviour, physical activity, cardiorespiratory fitness (CRF), and body composition parameters with risk of sleep-related breathing disorders (SRBD) in children with overweight/obesity. One-hundred and nine children $(10.0 \pm 1.1$ years old, 45 girls) with overweight $(n=27)$ and obesity $(n=82)$ were included. Television viewing time was self-reported by using the Spanish adaptation of the "Youth Activity Profile" (YAP) questionnaire. Sedentary time and physical activity were measured with accelerometry. CRF was assessed with the 20-m shuttle-run test and body composition parameters with Dual-energy X-ray absorptiometry. SRBD were evaluated by using the Spanish version of the Pediatric Sleep Questionnaire. Television viewing time was positively associated with risk of SRBD $(r=0.222$, $p=0.021)$. CRF was negatively correlated with risk of SRBD $(r=-0.210, p=0.030)$. Body composition parameters were positively associated with risk of SRBD (all $p<0.05)$, except fat mass index. Stepwise regression analyses showed that body mass index (BMI) explained the largest proportion of the variance in SRBD $\left(r^{2}=0.063, p=0.01\right)$ and television viewing time was the only one added after BMI $\left(r^{2}\right.$ change $\left.=0.048, p=0.022\right)$. This study supports the notion that higher body weight status negatively influences risk of SRBD and adds that unhealthy behaviours could contribute to worsen SRBD, related to an increased risk of cardiovascular diseases. All the significant association observed in this manuscript were of small magnitude, indicating than other factors in addition to the one hereby studied contribute to explain the variance in SRBD.
\end{abstract}


Keywords: sleep quality; preadolescents; childhood obesity; sedentarism; aerobic capacity; obstructive sleep apnea

\section{Introduction}

The International Classification of Sleep Disorders [1] divides sleep-related breathing disorders (SRBD) into a wide range of breathing abnormalities such as obstructive sleep apnea (OSA), central sleep apnea (CSA) syndromes, sleep-related hypoventilation and sleep-related hypoxemia disorders [2]. In pediatrics, the term SRBD also includes a variety of pathologies ranging from upper airway resistance syndrome and primary snoring to OSA-hypopnea syndrome [3]. SRBD are considered a major public health concern due to the high prevalence, closely related to obesity [4]. In childhood, SRBD are relatively common, with a prevalence of $12 \%$ [5]. More specifically, in a general population of children with 6 to 8 years, 10\% were affected by SRBD [6]. Further, the prevalence of OSA is about $1 \%$ to $6 \%$ whilst the prevalence of habitual snoring range from $1 \%$ to $27 \%$, in pediatric population [7-10].

It has been shown that SRBD often coexist with some morbidities related to the cardiovascular system (e.g., elevated blood pressure, and pulmonary hypertension) and the central nervous system (e.g., hyperactivity, excessive daytime sleepiness, cognitive deficits/academic problems, and behavioural problems), in childhood [11]. Specifically, current literature in children have shown that SRBD were associated with cardiovascular comorbidities and they impacted on sympathetic activity and, left and right, heart function [12]. Furthermore, OSA was related to an increased risk of resistant hypertension [13] and metabolic syndrome [14]. On the other hand, SRBD have been associated with multiple comorbidities such as poorer academic performance [15], lower certain aspects of behavioral functioning [16] and decreased parental-reported quality of life [11] at childhood. Therefore, studies examining the relationship between SRBD and health outcomes in children are needed.

Nowadays, obesity is one of the main public health-related problems, being considered one of the main risk factors for developing cardiovascular diseases, insulin resistance, hypertension and some types of cancer [17]. Pediatric obesity is associated with future mortality and morbidity, as well as with greater risk of cardiovascular diseases $[18,19]$. One study highlighted the importance of treating early overweight/obesity and SRBD in children to reduce the risk of future cardiovascular diseases [20]. Further, childhood obesity is another key risk factor for developing SRBD, especially in older children and adolescents. In fact, SRBD are presented in $26 \%$ to $33 \%$ of children with obesity [21] showing that the heavier you are, the higher the likelihood to suffer any SRBD [22-27]. Indeed, the prevalence of OSA, one of the most common causes of SRBD in children [7], ranges from $15 \%$ to $37 \%$ in non-obese children and from $33 \%$ to $76 \%$ in children with obesity depending on the definition of OSA, the age of the study sample, and the degree of obesity [28]. In a specific study of 12-year-old children with overweight/obesity, OSA prevalence was $44.6 \%$ [29]. In line with these assumptions, Mathew and Narang [30] concluded that children with overweight/obesity and adolescents could suffer OSA more frequently and may be more severe compared to lean children [30]. However, there is a need to deeply investigate how these factors are associated with risk of SRBD in childhood and, further, to study which of them, if any, is the best indicator of SRBD to ease its diagnostic.

Sedentary behaviour has been linked to SRBD [31]. For instance, many sedentary behaviours tend to be associated with an elevated risk of insomnia and sleep disturbance in the existing literature [32]. Indeed, low physical activity (PA) levels [33] and exercise capacity [34] have been associated to OSA. Likewise, most of the associated causes and comorbidities of SRBD are known to negatively impact cardiorespiratory fitness (CRF) [35].

Therefore, the aims of the present study were (i) to examine the association of sedentary behaviour, PA, CRF and body composition parameters with risk of SRBD; and (ii) to analyse which of these variables is the best explainer of SRBD in children with overweight/obesity. 


\section{Methods}

\subsection{Study Design and Participants}

The present cross-sectional study is under the framework of the ActiveBrains Project. A detailed description of the study protocol, aims and methods has been published elsewhere [36]. A total of 110 children with overweight/obesity from Granada (south of Spain) were recruited. Recruitment was done at the Unit of Pediatrics of the 'San Cecilio' and 'Virgen de las Nieves' University Hospitals and health care centers of Granada (Spain). Additionally, the head teacher of both private and public schools of Granada were contacted and advertisements in the local media were published [36]. Baseline data collection was performed from November 2014 to February 2016. Of them, one child was excluded for difficulties shown in reading comprehension, and thus, a total 109 children $(10.0 \pm 1.1$ years old, 45 girls) with overweight $(n=27)$ and obesity $(n=82)$ were included in the analyses.

Parents or legal guardians were informed about the purpose of the study and parental written informed consents for all participants were obtained. This study was conducted according to the Declaration of Helsinki. The study protocol was approved by the Ethics Committee on Human Research (CEIH) of the University of Granada and was registered in ClinicalTrials.gov (identifier: NCT02295072).

\subsection{Procedures and Measurements}

\subsubsection{Sedentary Behaviour and Physical Activity}

Television (TV) viewing time is known to be the most prevalent and common measure of leisure time sedentary behaviour [37,38]. TV viewing time was self-reported using the Spanish adaptation of the "Youth Activity Profile" questionnaire (YAP-S). The YAP-S was designed to be a self-administered 7-day recall questionnaire suitable for use in children to capture PA and sedentary behaviour [39]. The YAP questionnaire has been previously calibrated against accelerometer-determined sedentary behaviour and PA [39] and cross-validated in a different cohorts against accelerometer estimates as well $[40,41]$.

The complete time engaged in sedentary time was objectively measured using wrist-worn accelerometers (ActiGraph GT3X+, Pensacola, FL, USA). Briefly, participants were requested to wear the accelerometers in their non-dominant wrist for the complete $24 \mathrm{~h}$ of the day for 7 consecutive days. Accelerometers were initialized at a sampling frequency of $100 \mathrm{~Hz}$. Then, the raw accelerations were processed in the GGIR package v. 1.5-21 (https://cran.r-project.org/web/packages/GGIR/) in the R software (http://cran.r-project.org). Standard procedures were used to detect and impute non-wear time [42]. Sleep period time was detected using an automatized algorithm guided by reported sleep onset and waking-up times by the participants [43]. Euclidean norm minus one G (ENMO, $1 \mathrm{G} \sim 9.8 \mathrm{~m} / \mathrm{s}^{2}$ ) was calculated as (i.e., $\sqrt{x^{2}+y^{2}+z^{2}}-1 G$ ) over $5 \mathrm{~s}$ epochs after auto-calibration of the raw acceleration $[44,45]$. Finally, the cut points of Hildebrand et al. [46] were used to classify ENMO into sedentary time and moderate-to-vigorous physical activity (MVPA). Daily means were used for the analyses ( $\mathrm{min} /$ day).

\subsubsection{Cardiorespiratory Fitness}

CRF was assessed with the 20-m shuttle-run test as suggested in the ALPHA (Assessing Levels of Physical fitness and Health in Adolescents) health-related fitness test battery for youth [47]. It is known that this fitness test battery is feasible, reliable, valid and related to health in children [48-50]. Briefly, the test consists in running back and forth, between two lines $20 \mathrm{~m}$ apart, following an audio signal. Participants finished the test when they did not reach the line in two consecutive trials or stopped due to fatigue. We recorded the last completed lap and then, we translated it into an estimated maximal oxygen consumption measure $\left(\mathrm{VO}_{2} \mathrm{max}, \mathrm{mL} / \mathrm{kg} / \mathrm{min}\right)$ with the formula described by Léger [51]. 


\subsubsection{Body Composition Parameters}

Weight was assessed with an electronic scale (SECA 861, Hamburg, Germany), while height was measured using a precision stadiometer (SECA 225, Hamburg, Germany) to the nearest $0.1 \mathrm{~kg}$ and $\mathrm{cm}$, respectively. Body mass index (BMI) was calculated as weight $/$ height squared $\left(\mathrm{kg} / \mathrm{m}^{2}\right)$. Children were classified as overweight or obese using the sex- and age-specific international BMI cut offs proposed by the World Obesity Federation [52,53]. Waist circumference (WC) was measured using a homologated flexible steel tape (SECA, Hamburg, Germany). Weight, height, and WC were measured twice, and the average was considered for the analyses. Fat mass $(\mathrm{kg})$ and lean mass $(\mathrm{kg})$ were assessed by Dual-energy X-ray absorptiometry (DXA, Discovery densitometer from Hologic), following protocols used in previous studies [54,55]. Participants' fat mass index (FMI) and lean mass index (LMI) were calculated by dividing their outcome (i.e., fat mass or lean mass) by their squared height $\left(\mathrm{kg} / \mathrm{m}^{2}\right)$.

\subsubsection{Sleep-Related Breathing Disorders}

SRBD were evaluated with the Spanish version of the Pediatric Sleep Questionnaire (PSQ), which has shown high reliability and internal consistency [56]. This questionnaire was completed by parents, who should rate each item according to their child's usual sleep habits. This questionnaire has been validated for the identification of SRBD risk and covers a wide spectrum of breathing abnormalities ranging from primary snoring to central sleep apnea, sleep-related hypoventilation, or OSA [1].

A SRBD scale was calculated from the 22 items of the questionnaire. The SRBD scale consists of 22 closed response question-items of the reduced version of the PSQ, which are divided into three domains as follows [57]: snoring (nine items), sleepiness (seven items) and behaviour (six items). The answer options for each item include "yes", "no", and "I do not know". In the last domain of the questionnaire, the answers were structured in "never", "sometimes", "often" or "almost always". In order to be consistent with these answer options throughout the questionnaire, one of the sections was re-categorized as follows: "never" and "sometimes" answers were categorized as "no", whereas "often" and "almost always" answers were categorized as "yes". The overall scale was calculated as the sum of the affirmative answers divided by 22. Occasional missing answers or responses of "I do not know" were discounted from the denominator when calculating these proportions. Scores $>0.33$ were considered suggestive of high risk for a pediatric SRBD [57].

\subsubsection{Covariates}

Age, sex, and maternal education level were included as covariates. Maternal education was obtained by a self-reported questionnaire about the maximum education level achieved. Mothers' responses were classified as primary school, secondary school, and university degree completed.

\subsection{Statistical Analysis}

Descriptive characteristics are presented as means and standard deviations for continuous variables and as frequency and percentages for categorical variables. All variables were checked for normality. Sex differences were examined by $t$-tests and chi-squared tests for continuous and categorical variables, respectively.

Pearson's bivariate correlations were used to examine the association of sedentary behaviour, PA, CRF and body composition variables with SRBD scale. Hierarchical stepwise regressions were used to indicate the main explanatory variables of SRBD among sedentary behaviour, PA, CRF and body composition parameters. All the variables (i.e., age, sex, maternal education, TV viewing time, sedentary time, MVPA, CRF, BMI, FMI, LMI and WC) were included together in the regression. We calculated variance inflation factors (VIF) for the models performed and only considered those with VIF $<10$ to account for the risk of collinearity among explanatory variables. 
Additionally, participants were classified into low ( $\leq 1 \mathrm{~h} /$ day) and high $(>1 \mathrm{~h} /$ day) TV viewing groups. Although 2-h TV viewing has been related to negative health consequences [38], we considered that our sample, composed exclusively of children with overweight/obesity, could experience health consequences even with just $1 \mathrm{~h}$ of TV viewing per day. Differences between groups were analyzed with a one-way analysis of covariance (ANCOVA) adjusted for age, sex, and maternal education.

All analyses were performed using the Statistical Package for Social Science (IBM SPSS Statistics for Windows, version 22.0, Armonk, NY, USA). The level of significance was set at $p<0.05$.

\section{Results}

Descriptive characteristics of the participants stratified by sex are presented in Table 1.

Pearson's bivariate correlation analyses are presented in Table 2. In regard to sedentary behaviours, TV viewing time was positively associated with $\operatorname{SRBD}(r=0.222, p=0.021)$ whilst sedentary time was not $(r=0.129, p=0.193)$. MVPA was not significantly associated with SRBD $(r=0.054, p=0.585)$. CRF was negatively correlated with SRBD $(r=-0.210, p=0.030)$. Finally, all body composition parameters were positively associated with SRBD ( $\mathrm{r}$ ranging from 0.191 to 0.223 , all $p \leq 0.047)$, except FMI $(r=0.153$, $p=0.114)$.

Hierarchical stepwise regression for the association of sedentary behaviour, PA, CRF and body composition parameters with SRBD is presented in Table 3. BMI was the predictor which explained the largest proportion of the variance in $\operatorname{SRBD}\left(r^{2}=0.063, p=0.011\right)$. Among the rest of explainers, $\mathrm{TV}$ viewing time was the only one added to this model with a significant contribution $\left(r^{2}\right.$ change $=0.048$; $p=0.022$.

Table 1. Descriptive characteristics of the participants.

\begin{tabular}{|c|c|c|c|}
\hline & All & Boys & Girls \\
\hline$n(\%)$ & $109(100)$ & $64(59)$ & $45(41)$ \\
\hline Age (years) & $10.0 \pm 1.1$ & $10.2 \pm 1.1$ & $9.9 \pm 1.1$ \\
\hline \multicolumn{4}{|l|}{ Sedentary behaviour } \\
\hline \multicolumn{4}{|l|}{ Television viewing time, $n(\%)(n=107)$} \\
\hline None & $1(1)$ & $0(0)$ & $1(2)$ \\
\hline$<1$ h/day & $41(38)$ & $24(38)$ & $17(39)$ \\
\hline 1-2 h/day & $42(39)$ & $22(34)$ & $20(47)$ \\
\hline$<2-3$ h/day & $13(12)$ & $8(12)$ & $5(12)$ \\
\hline$>3 \mathrm{~h} /$ day & $10(9)$ & $10(16)$ & $0(0)$ \\
\hline Sedentary time (min/day) $(n=103)$ & $520.1 \pm 54.7$ & $521.3 \pm 52.0$ & $518.4 \pm 58.9$ \\
\hline \multicolumn{4}{|l|}{ Physical activity } \\
\hline \multicolumn{4}{|l|}{ Cardiorespiratory fitness } \\
\hline $20 \mathrm{~m}$ shuttle run test (laps) & $16.0 \pm 7.7$ & $17.2 \pm 8.1$ & $14.4 \pm 6.9$ \\
\hline $20 \mathrm{~m}$ shuttle run test $\left(\mathrm{VO}_{2 \max }, \mathrm{mL} / \mathrm{kg} / \mathrm{min}\right)^{a}$ & $40.7 \pm 2.7$ & $40.8 \pm 2.7$ & $40.6 \pm 2.7$ \\
\hline \multicolumn{4}{|l|}{ Body composition parameters } \\
\hline Weight $(\mathrm{kg})$ & $56.2 \pm 11.2$ & $57.1 \pm 11.2$ & $54.9 \pm 11.3$ \\
\hline Height $(\mathrm{cm})$ & $144.2 \pm 8.4$ & $145.0 \pm 8.0$ & $143.1 \pm 9.0$ \\
\hline Body mass index $\left(\mathrm{kg} / \mathrm{m}^{2}\right)$ & $26.8 \pm 3.6$ & $27.0 \pm 3.7$ & $26.6 \pm 3.5$ \\
\hline Fat mass index $\left(\mathrm{kg} / \mathrm{m}^{2}\right)$ & $11.8 \pm 2.9$ & $11.5 \pm 2.9$ & $12.1 \pm 2.8$ \\
\hline Lean mass index $\left(\mathrm{kg} / \mathrm{m}^{2}\right)$ & $14.0 \pm 1.4$ & $14.3 \pm 1.3$ & $13.5 \pm 1.4$ \\
\hline Waist circumference $(\mathrm{cm})$ & $90.2 \pm 9.9$ & $91.3 \pm 9.4$ & $88.7 \pm 10.5$ \\
\hline \multicolumn{4}{|l|}{ Sleep-related breathing disorders } \\
\hline SRBD scale (0 to 1$)$ & $0.2 \pm 0.1$ & $0.2 \pm 0.1$ & $0.2 \pm 0.1$ \\
\hline Presence of SRBD, $n(\%)$ & 17(16) & $10(16)$ & $7(16)$ \\
\hline
\end{tabular}

Data are presented as mean \pm standard deviation or frequency (\%). SRBD: Sleep-related breathing disorders, $\mathrm{VO}_{2 \max }$ : maximum oxygen consumption. ${ }^{a} 20 \mathrm{~m}$ shuttle run test $\left(\mathrm{VO}_{2 \mathrm{max}}\right)$ was estimated from the $20-\mathrm{m}$ shuttle run test by the formula described by Léger et al. [51]. 
Table 2. Pearson's bivariate correlation coefficients of sedentary behaviour, physical activity, cardiorespiratory fitness, and body composition parameters with sleep-related breathing disorders scale.

\begin{tabular}{ccc}
\hline & \multicolumn{2}{c}{ SRBD Scale (0 to 1) } \\
\cline { 2 - 3 } & $\boldsymbol{r}$ & $\boldsymbol{p}$ \\
\hline Sedentary behaviour & & \\
Television viewing time (h/day) & 0.222 & $\mathbf{0 . 0 2 1}$ \\
Sedentary time (min/day) & 0.129 & 0.193 \\
$\quad$ Physical activity & & \\
Moderate-to-vigorous physical activity (min/day) & 0.054 & 0.585 \\
Cardiorespiratory fitness $\left(\mathrm{VO}_{2 \mathrm{max}} \mathrm{mL} / \mathrm{kg} / \mathrm{min}\right)^{\mathrm{a}}$ & -0.210 & $\mathbf{0 . 0 3 0}$ \\
Body composition parameters & & \\
Body mass index $\left(\mathrm{kg} / \mathrm{m}^{2}\right)$ & 0.209 & $\mathbf{0 . 0 2 9}$ \\
Fat mass index $\left(\mathrm{kg} / \mathrm{m}^{2}\right)$ & 0.153 & 0.114 \\
Lean mass index $\left(\mathrm{kg} / \mathrm{m}^{2}\right)$ & 0.223 & $\mathbf{0 . 0 2 0}$ \\
Waist circumference $(\mathrm{cm})$ & 0.191 & $\mathbf{0 . 0 4 7}$ \\
\hline
\end{tabular}

Statistically significant values $(p<0.05)$ are shown in bold. SRBD: sleep-related breathing disorders. a Cardiorespiratory fitness $\left(\mathrm{VO}_{2 \max }\right)$ was estimated from the $20-\mathrm{m}$ shuttle run test by the formula described by Léger et al. [51].

Table 3. Hierarchical stepwise regression for the association of sedentary behaviour, physical activity, cardiorespiratory fitness, and body composition parameters with sleep-related breathing disorders scale $(n=102)$.

\begin{tabular}{ccccc}
\hline & $\boldsymbol{\beta}$ & $\boldsymbol{p}$-Value & Change $\boldsymbol{R}^{\mathbf{2}}$ & $\boldsymbol{R}^{\mathbf{2}}$ \\
\hline $\begin{array}{c}\text { Model 1 } \\
\text { Body mass index }\end{array}$ & 0.251 & $\mathbf{0 . 0 1 1}$ & 0.063 & 0.063 \\
$\quad$ Model 2 & & & 0.048 & 0.111 \\
$\quad$ Body mass index & 0.249 & $\mathbf{0 . 0 1 0}$ & & \\
Television viewing time & 0.220 & $\mathbf{0 . 0 2 2}$ & &
\end{tabular}

$\beta=$ standardized coefficients. Statistically significant values $(p<0.05)$ are shown in bold. Variables entered in the stepwise models: age, sex, maternal education, television viewing time, sedentary time, moderate-to-vigorous physical activity, cardiorespiratory fitness, body mass index, fat mass index, lean mass index, and waist circumference.

It is important to note that all the significant association observed in this manuscript were of small magnitude, indicating than other factors in addition to the one hereby studied contribute to explain the variance in SRBD.

ANCOVA analyses showed that children viewing TV for more than $1 \mathrm{~h} /$ day presented higher SRBD values than their peers after adjustment for age, sex and maternal education (mean difference $=0.057$; $p=0.031 ; F=4.779 ; \mathrm{df}=1$ ) (Figure 1$)$.

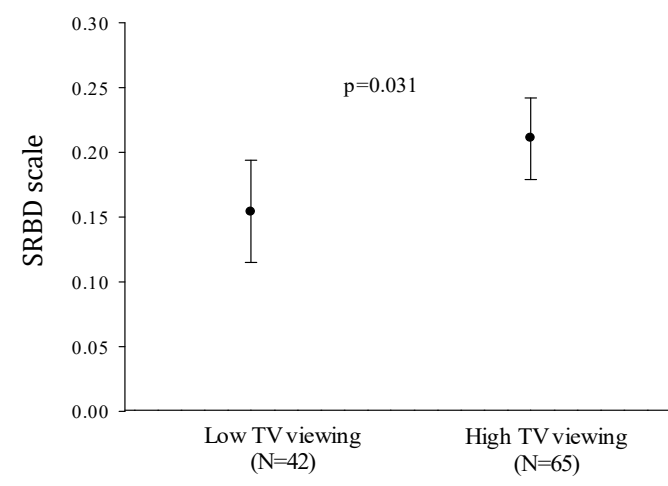

Figure 1. Differences in sleep-related breathing disorders between low and high TV viewing categories. Error bars represent mean and $95 \%$ confidence interval. Analyses are adjusted for age, sex, and maternal education. Low TV viewing: $\leq 1 \mathrm{~h} /$ day; High TV viewing: $>1 \mathrm{~h}$ /day. TV: television. SRBD: sleep-related breathing disorders. 


\section{Discussion}

The main findings of this study were: (1) TV viewing time and BMI parameters were positively associated with risk of SRBD. CRF was negatively associated with risk of SRBD; and (2) among the variables studied, BMI and TV viewing time were the best explainers of SRBD in children with overweight/obesity, explaining together around $11 \%$ of the variance in SRBD.

A previous study has shown that sedentary behaviour such as TV viewing (TV mobile screen watching) is strongly related to childhood obesity [58]. Additionally, it is shown that higher durations of TV viewing and screen time were associated with poorer body composition [59]. Our findings contribute to the existing knowledge by suggesting that those children with overweight/obesity who spend more than $1 \mathrm{~h}$ viewing TV also showed higher SRBD values. Likewise, TV viewing was a stronger indicator of SRBD than objectively assessed sedentary time and MVPA. Paavonen et al. [60] found that TV viewing was related to shorter sleep duration, sleeping disorders, and overall sleep disturbances in 5 to 6-year-old normal weight children. Our findings complement these ones by suggesting the same association in older children, i.e., 8.5 to 12 -year-olds. Of note, a cut point of $2 \mathrm{~h}$ of TV viewing time is usually considered as being malign for health [38]. However, since our participants were children with overweight/obesity, we assumed that lower doses of TV viewing time are especially harmful for this sample, and so, $1 \mathrm{~h}$ of TV viewing time was considered to compare subgroups in our study. Concerning sedentary time measured through accelerometers, we did not observe any association with SRBD. The lack of capacity to discern between sedentary activities by the accelerometer could partially explain this finding. Similarly, no relationship between MVPA and SRBD was found. Although we have not found studies testing the associations between objectively-assessed MVPA and SRBD, it seems that 40 min per day of vigorous aerobic exercise could improve symptoms of SRBD in overweight 7 to 11-year-old children [61].

CRF is an important health marker, not only in adults but also in children and adolescents [62]. In consonance with previous studies [35,63], we found that CRF was negatively associated with SRBD values. Although this association was weak, our sample size was limited; thus, further studies with larger sample sizes are needed to estimate the real effect size of this association. For instance, Stojek et al. [63] found that higher levels of CRF were closely linked to less SRBD in inactive children with overweight/obesity aged 7 to 11 years. A possible explanation could be that the high oxygen demanding produced by CRF could improve the efficiency of the children's cardiorespiratory system and, therefore, reduce SRBD.

Current literature provides evidence that children with overweight/obesity commonly present SRBD [22-27]. Longitudinal studies showed that overweight/obesity status in adolescents was strongly associated with increased mortality in adulthood due to cardiovascular diseases or other obesity-related risk factors [64]. One study found that a higher body fat percentage at the age of 6 to 8 years was associated with a higher risk of having SRBD 2 years later [65]. Verhulst et al. [24] found that fat distribution, as represented by WC, waist-to-hip ratio, or fat mass percentage were associated with central sleep apnea but not with OSA in children with overweight/obesity. In concordance with our findings, a questionnaire study in children who were on average 9 years old, observed that WC was correlated with risk of SRBD [66]. Additionally, WC was associated with all levels of SRBD [25] and an increased amount of visceral fat was associated with serious manifestations of SRBD [67] in a population sample of children. Likewise, Bhatia et al. [68] observed that BMI was positively associated with sleep problems (i.e., total arousal index and desaturation index) in children with overweight/obesity. In regard to DXA measures, they found that total body fat mass and trunk fat mass were related to some SRBD indicators, but they did not included FMI among their measures. Specifically, they concluded that the value of fat mass to study SRBD depends in the distribution of the fat over the body, which could explain the lack of association that we found after considering height when calculate FMI. In contrast, our results suggested that LMI could be a better indicator of SRBD than FMI. A possible explanation could be that children with more LMI have higher obesity levels since they have to carry more fat and also have bigger nocturnal work of breathing and, thus, they develop more 
lean mass. Furthermore, sarcopenic obesity has been associated with SRBD in adults, but not obesity in general. The hypothesis is that an excess of fat is a predictor of SRBD only when the lean mass is low [69-71]. However, in children, loss of lean mass is not a common problem, and little has been studied about body composition in relation to SRBD. Further studies using gold-standard methods for body composition parameters are needed to contrast our findings in children with overweight/obesity.

BMI has been very criticized for its lack of ability to distinguish between fat and lean tissues, but also a recent study showed that this index is better in the prediction of mortality than fat mass measured by a gold-standard method [72]. In regard to SRBD, we found something similar; BMI was a stronger explainer of SRBD than any other body composition outcome measured by a gold-standard (i.e., DXA). Other body composition parameters such as LMI or WC were associated with SRBD, but they were unable to explain a proportion of variance in SRBD more than those already explained by BMI. Andersen et al. found that an increased BMI was associated with increased apnea-hypopnea index and significantly risk of having OSA in children aged 7 to 18 years with overweight/obesity [29]. These results differ from those provided by Carotenuto et al. [66], who suggested that visceral fat (expressed as WC) was a more reliable measure than total adiposity (expressed as BMI) to predict the risk for developing SRBD in children and adolescents with obesity. Differences in study samples (i.e., participants' age) and methodology (i.e., different questionnaires) might be responsible for the differences between these findings and ours. In addition, they only included children with obesity, while we also considered overweight children, which could partially explain the signification of BMI in our sample compared to the sample of Carotenuto et al. [66]. More studies are needed for a better understanding of the relationships between body composition and SRBD in children with overweight/obesity.

Among the explanatory variables of SRBD included in the present study (i.e., sedentary behaviour, PA, CRF and body composition parameters), we found that BMI and TV viewing time were the strongest ones, explaining the largest proportion of the variance in SRBD. None of the rest of outcomes contributed to the explanation already shown by BMI and TV viewing time. Although more studies are needed to confirm this, these findings suggest that interventions oriented to reduce BMI and TV viewing time through the modification of lifestyle habits and practices of physical exercise could be useful for the treatment of SRBD in children with overweight/obesity, even if the association is not strong enough.

The high prevalence of obesity and its health-related problems, such as SRBD, in the current pediatric population makes crucial the investigation on environmental factors associated with this disorder. Previous research has shown links of sedentary behaviour, PA and body composition parameters with SRBD in pediatric population. Our study complements the current knowledge by: (1) confirming these findings, despite the weak link, and adding more information in the literature due to the lack of knowledge on this topic, and (2) testing which of the factors could be of predominant interest to treat SRBD in children with overweight/obesity. However, only $11 \%$ of the variation in SRBD was explained by the predictors included. There is an important amount of the variation which is explained by factors not included in our models. Whether this $11 \%$ is enough to help in the diagnostic of SRBD from early ages is something to be investigated in future research.

Some limitations of the present study need to be acknowledged. Firstly, this is a cross-sectional study; hence, it does not allow us to infer causality for any of the associations studied. Secondly, a gold standard was not used to identify risk of SRBD and our data were obtained from parental questionnaires instead of polysomnographic data; therefore, its accuracy in evaluating SRBD is limited. Thirdly, the no inclusion of normal weight children cannot allow us the comparison between different weight status populations. Fourthly, our sample size was limited; thus, even more powerful studies with larger sample sizes are needed to confirm or contrast our findings. Caution is advised with the interpretation of these findings regarding younger ages, when other factors may be major determinants of SRBD (e.g., adenotonsillar). Finally, there could be other potential explanatory factors for SRBD in addition to those hereby studied that need to be investigated in future studies. The strengths of 
this study were: (1) the inclusion of objectively measured, sedentary time, and PA with accelerometry; (2) the inclusion of reliable, valid, and related to health field-based fitness tests in children [48-50] and

(3) the reliable and valid measures of body composition parameters.

\section{Conclusions}

Our results suggest that sedentary time, CRF, and body composition parameters were associated with risk of SRBD in children with overweight/obesity-TV viewing time and BMI being the strongest explainers of SRBD. This study supports the notion that higher body weight status negatively influences SRBD and adds that unhealthy behaviours such as high TV viewing time could independently contribute to worsen SRBD. PA interventions focused on reducing sedentary behaviours such as TV viewing time and improving both CRF and body composition parameters could be a good strategy to treat SRBD prevalence in children with overweight/obesity and to reduce cardiovascular diseases risk in adulthood. All the significant association observed in this manuscript were of small magnitude, indicating that other factors in addition to the one hereby studied contribute to explain the variance in SRBD. Further randomized controlled trials studies are needed in order to contrast or corroborate our findings.

Author Contributions: Conceptualisation, F.B.O.; formal analysis, L.V.T.-L., C.C.-S., J.H.M. and M.A.-R.; funding acquisition, F.B.O.; investigation, L.V.T.-L., C.C.-S., J.H.M., A.P.-F., P.S.-U. and P.M.-G.; methodology, C.C.-S. and F.B.O.; project administration, F.B.O.; supervision, C.C.-S. and F.B.O.; visualization, L.V.T.-L.; writing-original draft, L.V.T.-L.; writing—review and editing, C.C.-S., J.H.M., M.A.-R., A.P.-F., P.S.-U., P.M.-G. and F.B.O. All authors have read and agreed to the published version of the manuscript.

Funding: This work is part of a PhD thesis conducted in the Official Doctoral Programme in Biomedicine of the University of Granada, Spain. The ActiveBrains project was funded by the Spanish Ministry of Economy and Competitiveness and the "Fondo Europeo de Desarrollo Regional (FEDER)" (DEP2013-47540, DEP2016-79512-R, DEP2017-91544-EXP and RYC-2011-09011). L.V.T.-L. is supported by a Grant from the Spanish Ministry of Science, Innovation and Universities (FPU17/04802) and by a Grant from the University of Granada, Plan Propio de Investigación y Transferencia 2018 (Research Initiation Grants for official Master's students). J.H.M. and A.P.-F. are supported by a Grant from the Spanish Ministry of Education, Culture and Sport (FPU15/02645 and FPU 16/02760, respectively). C.C.-S. is supported by a grant from the Spanish Ministry of Economy and Competitiveness (BES-2014-068829); by the Government of Andalusian, Integrated Territorial Initiative 2014-2020 for the province of Cádiz (PI-0002-2017); and the Spanish Ministry of Science and Innovation (FJC2018-037925-I). M.A.-R. is supported by a Predoctoral Research Grant from the University Jaume I (PREDOC/2015/13 and E-2017-13). P.S.-U. is supported by a grant from CONICYT/BECAS Chile/72180543. Additional support was obtained from the University of Granada, Plan Propio de Investigación 2016, Excellence actions: Units of Excellence, Scientific Excellence Unit on Exercise and Health (UCEES), by the Junta de Andalucía, Consejería de Conocimiento, Investigación y Universidades, and European Regional Development Funds (ref. SOMM17/6107/UGR). In addition, funding was provided by the SAMID III network, RETICS, funded by the PNI + D + I 2017-2021 (Spain), ISCIIISub-Directorate General for Research Assessment and Promotion, the European Regional Development Fund (ERDF) (Ref. RD16/0022), the EXERNET Research Network on Exercise and Health in Special Populations (DEP2005-00046/ACTI) and the European Union's 2020 research and innovation program under grant agreement No.667302.

Acknowledgments: We are grateful to Ana Yara Postigo-Fuentes for her assistance with English language.

Conflicts of Interest: The authors declare no conflict of interest.

\section{References}

1. American Academy of Sleep Medicine. International Classification of Sleep Disorders, 3rd ed.; American Academy of Sleep Medicine: Darien, IL, USA, 2014.

2. Sateia, M.J. International classification of sleep disorders: Third edition: Highlights and Modifications. Chest 2014, 146, 1387-1394. [CrossRef]

3. Tsara, V.; Amfilochiou, A.; Papagrigorakis, J.; Georgopoulos, D.; Liolios, E.; Kadiths, A.; Koudoumnakis, E.; Aulonitou, E.; Emporiadou, M.; Tsakanikos, M.; et al. Guidelines for Diagnosing and Treating Sleep related Breathing Disorders in Adults and Children (Part 3: Obstructive Sleep Apnea in Children, Diagnosis and Treatment). Hippokratia 2010, 14, 57-62.

4. Ma, Y.; Peng, L.; Kou, C.; Hua, S.; Yuan, H. Associations of Overweight, Obesity and Related Factors with Sleep-Related Breathing Disorders and Snoring in Adolescents: A Cross-Sectional Survey. Int. J. Environ. Res. Public Health 2017, 14, 194. [CrossRef] 
5. Scalzitti, N.J.; Sarber, K.M. Diagnosis and perioperative management in pediatric sleep-Disordered breathing. Pediatr. Anesth. 2018, 28, 940-946. [CrossRef]

6. Ikävalko, T.; Tuomilehto, H.; Pahkala, R.; Tompuri, T.; Laitinen, T.; Myllykangas, R.; Vierola, A.; Lindi, V.; Närhi, M.; Lakka, T.A. Craniofacial morphology but not excess body fat is associated with risk of having sleep-disordered breathing-The PANIC Study (a questionnaire-based inquiry in 6-8-year-olds). Eur. J. Pediatr. 2012, 171, 1747-1752. [CrossRef]

7. Dehlink, E.; Tan, H. Update on paediatric obstructive sleep apnoea. J. Thorac. Dis. 2016, 8, 224-235.

8. Urquhart, D.S.; Hill, E.A.; Morley, A. Sleep-Disordered breathing in children. Paediatr. Child Health (Oxford) 2017, 27, 328-336. [CrossRef]

9. Marcus, C.L.; Brooks, L.J.; Ward, S.D.; Draper, K.A.; Gozal, D.; Halbower, A.C.; Jones, J.; Lehmann, C.; Schechter, M.S.; Sheldon, S.; et al. Diagnosis and Management of Childhood Obstructive Sleep Apnea Syndrome. Am. Acad. Pediatr. 2012, 130, e714-e755.

10. Lumeng, J.C.; Chervin, R.D. Epidemiology of Pediatric Obstructive Sleep Apnea. Proc. Am. Thorac. Soc. 2008, 5, 242-252. [CrossRef]

11. Kaditis, A.G.; Alvarez, M.L.A.; Boudewyns, A.; Alexopoulos, E.I.; Ersu, R.; Joosten, K.; Larramona, H.; Miano, S.; Narang, I.; Trang, H.; et al. Obstructive sleep disordered breathing in 2-To 18-Year-Old children: Diagnosis and management. Eur. Respir. J. 2016, 47, 69-94. [CrossRef]

12. Ehsan, Z.; Ishman, S.L.; Kimball, T.R.; Zhang, N.; Zou, Y.; Amin, R.S. Longitudinal Cardiovascular Outcomes of Sleep Disordered Breathing in Children: A Meta-Analysis and Systematic Review. Sleep 2017, 40. [CrossRef]

13. Hou, H.; Zhao, Y.; Yu, W.; Dong, H.; Xue, X.; Ding, J.; Xing, W.; Wang, W. Association of obstructive sleep apnea with hypertension: A systematic review and meta-Analysis. J. Glob. Health 2018, 8. [CrossRef]

14. Xu, S.; Wan, Y.; Xu, M.; Ming, J.; Xing, Y.; An, F.; Ji, Q. The association between obstructive sleep apnea and metabolic syndrome: A systematic review and meta-Analysis. BMC Pulm. Med. 2015, 15, 105. [CrossRef]

15. Galland, B.; Spruyt, K.; Dawes, P.; McDowall, P.S.; Elder, D.; Schaughency, E. Sleep disordered breathing and academic performance: A meta-analysis. Pediatrics 2015, 136, e934-e946. [CrossRef]

16. Beebe, D.W.; Ris, M.D.; Kramer, M.E.; Long, E.; Amin, R. The association between sleep disordered breathing, academic grades, and cognitive and behavioral functioning among overweight subjects during middle to late childhood. Sleep 2010, 33, 1447-1456. [CrossRef]

17. Guh, D.P.; Zhang, W.; Bansback, N.; Amarsi, Z.; Birmingham, C.L.; Anis, A.H. The incidence of co-morbidities related to obesity and overweight: A systematic review and meta-Analysis. BMC Public Health 2009, 9, 88. [CrossRef]

18. GBD 2015 Obesity Collaborators; Afshin, A.; Forouzanfar, M.H.; Reitsma, M.B.; Sur, P.; Estep, K.; Lee, A.; Marczak, L.; Mokdad, A.H.; Moradi-Lakeh, M.; et al. Health effects of overweight and obesity in 195 countries over 25 years. N. Engl. J. Med. 2017, 377, 13-27.

19. Reilly, J.J.; Kelly, J. Long-Term impact of overweight and obesity in childhood and adolescence on morbidity and premature mortality in adulthood: Systematic review. Int. J. Obes. 2011, 35, 891-898. [CrossRef]

20. Walter, L.M.; Tamanyan, K.; Limawan, A.P.; Biggs, S.N.; Weichard, A.J.; Davey, M.J.; Nixon, G.M.; Horne, R.S.C. Overweight and obese children with sleep disordered breathing have elevated arterial stiffness. Sleep Med. 2018, 48, 187-193. [CrossRef]

21. Wing, Y.K.; Hui, S.H.; Pak, W.M.; Ho, C.K.; Cheung, A.; Li, A.M.; Fok, T.F. A controlled study of sleep related disordered breathing in obese children. Arch. Dis. Child. 2003, 88, 1043-1047. [CrossRef]

22. Bhattacharjee, R.; Hakim, F.; Gozal, D. Sleep, sleep-Disordered breathing and lipid homeostasis: Translational evidence from murine models and children. Clin. Lipidol. 2012, 7, 203-214. [CrossRef]

23. Verhulst, S.L.; Van Gaal, L.; De Backer, W.; Desager, K. The prevalence, anatomical correlates and treatment of sleep-disordered breathing in obese children and adolescents. Sleep Med. Rev. 2008, 12, 339-346. [CrossRef]

24. Verhulst, S.L.; Schrauwen, N.; Haentjens, D.; Suys, B.; Rooman, R.P.; Van Goal, L.; De Backer, W.A.; Desager, K.N. Sleep-Disordered breathing in overweight and obese children and adolescents: Prevalence, characteristics and the role of fat distribution. Arch. Dis. Child. 2007, 92, 205-208. [CrossRef]

25. Bixler, E.O.; Vgontzas, A.N.; Lin, H.-M.; Liao, D.; Calhoun, S.; Vela-Bueno, A.; Fedok, F.; Vlasic, V.; Graff, G. Sleep Disordered Breathing in Children in a General Population Sample: Prevalence and Risk Factors. Sleep 2009, 32, 731-736. [CrossRef] 
26. Tsaoussoglou, M.; Bixler, E.O.; Calhoun, S.; Chrousos, G.P.; Sauder, K.; Vgontzas, A.N. Sleep-Disordered Breathing in Obese Children Is Associated with Prevalent Excessive Daytime Sleepiness, Inflammation, and Metabolic Abnormalities. J. Clin. Endocrinol. Metab. 2010, 95, 143-150. [CrossRef]

27. Brunetti, L.; Tesse, R.; Miniello, V.L.; Colella, I.; Delvecchio, M.; Logrillo, V.P.; Francavilla, R.; Armenio, L. Sleep-Disordered breathing in obese children: The Southern Italy experience. Chest 2010, 137, 1085-1090. [CrossRef]

28. Andersen, I.G.; Holm, J.C.; Homøe, P. Obstructive sleep apnea in obese children and adolescents, treatment methods and outcome of treatment-A systematic review. Int. J. Pediatr. Otorhinolaryngol. 2016, 87, 190-197. [CrossRef]

29. Andersen, I.G.; Holm, J.C.; Homøe, P. Obstructive sleep apnea in children and adolescents with and without obesity. Eur. Arch. Oto-Rhino-Laryngol. 2019, 276, 871-878. [CrossRef]

30. Mathew, J.L.; Narang, I. Sleeping too Close Together: Obesity and Obstructive Sleep Apnea in Childhood and Adolescence. Paediatr. Respir. Rev. 2014, 15, 211-218. [CrossRef]

31. Kline, C.E.; Krafty, R.T.; Mulukutla, S.; Hall, M.H. Associations of sedentary time and moderate-Vigorous physical activity with sleep-Disordered breathing and polysomnographic sleep in community-Dwelling adults. Sleep Breath 2017, 21, 427-434. [CrossRef]

32. Yang, Y.; Shin, J.C.; Li, D.; An, R. Sedentary Behavior and Sleep Problems: A Systematic Review and Meta-Analysis. Int. J. Behav. Med. 2017, 24, 481-492. [CrossRef]

33. Mendelson, M.; Bailly, S.; Marillier, M.; Flore, P.; Borel, J.C.; Vivodtzev, I.; Doutreleau, S.; Verges, S.; Tamisier, R.; Pépin, J.L. Obstructive sleep apnea syndrome, objectively measured physical activity and exercise training interventions: A systematic review and meta-analysis. Front. Neurol. 2018, 9, 1-14. [CrossRef]

34. Beitler, J.R.; Awad, K.M.; Bakker, J.P.; Edwards, B.A.; DeYoung, P.; Djonlagic, I.; Forman, D.E.; Quan, S.F.; Malhotra, A. Obstructive sleep apnea is associated with impaired exercise capacity: A cross-Sectional study. J. Clin. Sleep Med. 2014, 10, 1199-1204. [CrossRef]

35. Vanhecke, T.E.; Franklin, B.A.; Ajluni, S.C.; Sangal, R.B.; McCullough, P.A. Cardiorespiratory fitness and sleep-related breathing disorders. Expert Rev. Cardiovasc. Ther. 2008, 6, 745-758. [CrossRef]

36. Cadenas-Sánchez, C.; Mora-González, J.; Migueles, J.H.; Martín-Matillas, M.; Gómez-Vida, J.; Escolano-Margarit, M.V.; Maldonado, J.; Enriquez, G.M.; Pastor-Villaescusa, B.; de Teresa, C.; et al. An exercise-Based randomized controlled trial on brain, cognition, physical health and mental health in overweight/obese children (ActiveBrains project): Rationale, design and methods. Contemp. Clin. Trials 2016, 47, 315-324. [CrossRef]

37. Keadle, S.K.; Arem, H.; Moore, S.C.; Sampson, J.N.; Matthews, C.E. Impact of changes in television viewing time and physical activity on longevity: A prospective cohort study. Int. J. Behav. Nutr. Phys. Act. 2015, 12, 1-11. [CrossRef]

38. Tremblay, M.S.; LeBlanc, A.G.; Kho, M.E.; Saunders, T.J.; Larouche, R.; Colley, R.C.; Goldfield, G.; Gorber, S.C. Systematic review of sedentary behaviour and health indicators in school-Aged children and youth. Int. J. Behav. Nutr. Phys. Act. 2011, 8, 98. [CrossRef]

39. Saint-Maurice, P.F.; Welk, G.J. Web-Based assessments of physical activity in youth: Considerations for design and scale calibration. J. Med. Internet Res. 2014, 16. [CrossRef]

40. Saint-Maurice, P.F.; Welk, G.J. Validity and calibration of the youth activity profile. PLoS ONE 2015, 10, e0143949. [CrossRef]

41. Fairclough, S.J.; Christian, D.L.; Saint-Maurice, P.F.; Hibbing, P.R.; Noonan, R.J.; Welk, G.J.; Dixon, P.M.; Boddy, L.M. Calibration and validation of the youth activity profile as a physical activity and sedentary behaviour surveillance tool for english youth. Int. J. Environ. Res. Public Health 2019, 16, 3711. [CrossRef]

42. van Hees, V.T.; Renström, F.; Wright, A.; Gradmark, A.; Catt, M.; Chen, K.Y.; Löf, M.; Bluck, L.; Pomeroy, J.; Wareham, N.J.; et al. Estimation of daily energy expenditure in pregnant and Non-Pregnant women using a Wrist-Worn Tri-Axial accelerometer. PLoS ONE 2011, 6, e22922. [CrossRef]

43. van Hees, V.T.; Sabia, S.; Anderson, K.N.; Denton, S.J.; Oliver, J.; Catt, M.; Abell, J.G.; Kivimäki, M.; Trenell, M.I.; Singh-Manoux, A. A novel, open access method to assess sleep duration using a wrist-Worn accelerometer. PLoS ONE 2015, 10, e0142533. [CrossRef]

44. van Hees, V.T.; Gorzelniak, L.; Dean León, E.C.; Eder, M.; Pias, M.; Taherian, S.; Ekelund, U.; Renström, F.; Franks, P.W.; Horsch, A.; et al. Separating Movement and Gravity Components in an Acceleration Signal and Implications for the Assessment of Human Daily Physical Activity. PLoS ONE 2013, 8, e61691. [CrossRef] 
45. van Hees, V.T.; Fang, Z.; Langford, J.; Assah, F.; Mohammad, A.; da Silva, I.C.M.; Trenell, M.I.; White, T.; Wareham, N.J.; Brage, S. Autocalibration of accelerometer data for free-living physical activity assessment using local gravity and temperature: An evaluation on four continents. J. Appl. Physiol. 2014, 117, 738-744. [CrossRef]

46. Hildebrand, M.; Van Hees, V.T.; Hansen, B.H.; Ekelund, U. Age group comparability of raw accelerometer output from wrist-And hip-Worn monitors. Med. Sci. Sports Exerc. 2014, 46, 1816-1824. [CrossRef]

47. Ruiz, J.R.; Castro-Piñero, J.; España-Romero, V.; Artero, E.G.; Ortega, F.B.; Cuenca, M.A.M.; Enez-Pavón, D.J.; Chillón, P.; Girela-Rejón, M.J.; Mora, J.; et al. Field-Based fitness assessment in young people: The ALPHA health-Related fitness test battery for children and adolescents. Br. J. Sports Med. 2011, 45, 518-524. [CrossRef]

48. Artero, E.G.; España-Romero, V.; Castro-Piero, J.; Ortega, F.B.; Suni, J.; Castillo-Garzon, M.J.; Ruiz, J.R. Reliability of field-Based fitness tests in youth. Int. J. Sports Med. 2011, 32, 159-169. [CrossRef]

49. Castro-Piñero, J.; Artero, E.G.; España-Romero, V.; Ortega, F.B.; Sjostrom, M.; Suni, J.; Ruiz, J.R. Criterion-Related validity of field-Based fitness tests in youth: A systematic review. Br. J. Sport. Med. 2010, 44, 934-943. [CrossRef]

50. Ruiz, J.R.; Castro-Piñero, J.; Artero, E.G.; Ortega, F.B.; Sjöström, M.; Suni, J.; Castillo, M.J. Predictive validity of health-related fitness in youth: A systematic review. Br. J. Sports Med. 2009, 43, 909-923. [CrossRef]

51. Léger, L.A.; Mercier, D.; Gadoury, C.; Lambert, J. The multistage 20 metre shuttle run test for aerobic fitness. J. Sports Sci. 1988, 6, 93-101. [CrossRef]

52. Cole, T.J.; Lobstein, T. Extended international (IOTF) body mass index cut-Offs for thinness, overweight and obesity. Pediatr. Obes. 2012, 7, 284-294. [CrossRef] [PubMed]

53. Bervoets, L.; Massa, G. Defining morbid obesity in children based on BMI 40 at age 18 using the extended international (IOTF) cut-offs. Pediatr. Obes. 2014, 9, e94-e98. [CrossRef] [PubMed]

54. Gracia-Marco, L.; Moreno, L.A.; Ortega, F.B.; Len, F.; Sioen, I.; Kafatos, A.; Martinez-Gomez, D.; Widhalm, K.; Castillo, M.J.; Vicente-Rodrguez, G. Levels of physical activity that predict optimal bone mass in adolescents: The HELENA study. Am. J. Prev. Med. 2011, 40, 599-607. [CrossRef] [PubMed]

55. Gracia-Marco, L.; Ortega, F.B.; Jiménez-Pavón, D.; Rodríguez, G.; Castillo, M.J.; Vicente-Rodríguez, G.; Moreno, L.A. Adiposity and bone health in Spanish adolescents. the HELENA study. Osteoporos. Int. 2012, 23, 937-947. [CrossRef] [PubMed]

56. Vila, M.T.; Torres, A.M.; Soto, B.B. Spanish Version of the Pediatric Sleep Questionnaire (PSQ). A useful instrument in investigation of sleep disturbances in childhood. Reliability analysis. An. Pediatr. 2007, 66, 121-128.

57. Chervin, R.D.; Weatherly, R.A.; Garetz, S.L.; Ruzicka, D.L.; Giordani, B.J.; Hodges, E.K.; Dillon, J.E.; Guire, K.E. Pediatric sleep questionnaire. Prediction of sleep apnea and outcomes. Arch. Otolaryngol. Head Neck Surg. 2007, 133, 216-222. [CrossRef]

58. Rosiek, A.; Maciejewska, N.F.; Leksowski, K.; Rosiek-Kryszewska, A.; Leksowski, Ł. Effect of television on obesity and excess of weight and consequences of health. Int. J. Environ. Res. Public Health 2015, 12, 9408-9426. [CrossRef]

59. Carson, V.; Hunter, S.; Kuzik, N.; Gray, C.E.; Poitras, V.J.; Chaput, J.; Saunders, T.J.; Katzmarzyk, P.T.; Okely, A.D.; Gorber, S.C.; et al. Systematic review of sedentary behaviour and health indicators in school-Aged children and youth: An update. Appl. Physiol. Nutr. Metab. 2016, 41, S240-S265. [CrossRef]

60. Paavonen, E.J.; Pennonen, M.; Roine, M.; Valkonen, S.; Lahikainen, A.R. TV exposure associated with sleep disturbances in 5- to 6-year-old children. J. Sleep Res. 2006, 15, 154-161. [CrossRef]

61. Davis, C.L.; Tkacz, J.; Gregoski, M.; Boyle, C.A.; Lovrekovic, G. Aerobic Exercise and Snoring in Overweight Children: A Randomized Controlled Trial. Obesity (Silver Spring) 2006, 14, 1985-1991. [CrossRef]

62. Ortega, F.; Ruiz, J.; Castillo, M.; Sjöström, M. Physical fitness in childhood and adolescence: A powerful marker of health. Int. J. Obes. 2008, 32, 1-11. [CrossRef]

63. Stojek, M.M.K.; Montoya, A.K.; Drescher, C.F.; Newberry, A.; Sultan, Z.; Williams, C.F.; Pollock, N.K.; Davis, C.L. Fitness, Sleep-Disordered Breathing, Symptoms of Depression, and Cognition in Inactive Overweight Children: Mediation Models. Public Health Rep. 2017, 132, 65S-73S. [CrossRef]

64. Twig, G.; Afek, A.; Derazne, E.; Tzur, D.; Cukierman-Yaffe, T.; Gerstein, H.C.; Tirosh, A. Diabetes risk among overweight and obese metabolically healthy young adults. Diabetes Care 2014, 37, 2989-2995. [CrossRef] 
65. Ikävalko, T.; Närhi, M.; Eloranta, A.M.; Lintu, N.; Myllykangas, R.; Vierola, A.; Tuomilehto, H.; Lakka, T.; Pahkala, R. Predictors of sleep disordered breathing in children: The PANIC study. Eur. J. Orthod. 2018, 40, 268-272. [CrossRef]

66. Carotenuto, M.; Bruni, O.; Santoro, N.; del Giudice, E.M.; Perrone, L.; Pascotto, A. Waist circumference predicts the occurrence of sleep-disordered breathing in obese children and adolescents: A questionnaire-Based study. Sleep Med. 2006, 7, 357-361. [CrossRef]

67. Bixler, E.O.; Fernandez-Mendoza, J.; Liao, D.; Calhoun, S.; Rodriguez-Colon, S.M.; Gaines, J.; He, F.; Vgontzas, A.N. Natural history of sleep disordered breathing in prepubertal children transitioning to adolescence. Eur. Respir. J. 2016, 47, 1402-1409. [CrossRef]

68. Bhatia, R.; Lesser, D.J.; Oliveira, F.G.S.A.; Tran, W.H.; Keens, T.G.; Khoo, M.C.K.; Ward, S.L.D. Body fat composition: A predictive factor for sleep related breathing disorder in obese children. J. Clin. Sleep Med. 2015, 11, 1039-1045. [CrossRef]

69. Piovezan, R.D.; Hirotsu, C.; Moizinho, R.; de Sá Souza, H.; D’Almeida, V.; Tufik, S.; Poyares, D. Associations between sleep conditions and body composition states: Results of the EPISONO study. J. Cachexia Sarcopenia Muscle 2019, 10, 962-973. [CrossRef]

70. Lovin, S.; Bercea, R.; Cojocaru, C.; Rusu, G.; Mihãescu, T. Body composition in obstructive sleep apneahypopnea syndrome: Bio-impedance reflects the severity of sleep apnea. Multidiscip. Respir. Med. 2010, 5, 44-49. [CrossRef]

71. Kuźnar-Kamińska, B.; Grabicki, M.; Trafas, T.; Szulińska, M.; Cofta, S.; Piorunek, T.; Brajer-Luftmann, B.; Nowicka, A.; Bromińska, B.; Batura-Gabryel, H. Body composition, anthropometric indices and hydration status of obstructive sleep apnea patients: Can cachexia coexist with obesity? Adv. Exp. Med. Biol. 2017, 1020, 43-51.

72. Ortega, F.B.; Sui, X.; Lavie, C.J.; Blair, S.N. Body Mass Index, the Most Widely Used but also Widely Criticized Index: Would a Gold-Standard Measure of Total Body Fat be a Better Predictor of Cardiovascular Disease Mortality? Mayo Clin. Proc. 2016, 91, 443-455. [CrossRef] [PubMed]

(C) 2020 by the authors. Licensee MDPI, Basel, Switzerland. This article is an open access article distributed under the terms and conditions of the Creative Commons Attribution (CC BY) license (http://creativecommons.org/licenses/by/4.0/). 